\title{
ANALYSIS AND EVALUATION OF THE RISK OF INSOLVENCY AND BANCRUPTCY OF COMPANIES FROM THE FOOD INDUSTRY IN STARA ZAGORA REGION
}

\author{
O. Milev* \\ Department “Economics", Faculty of Economics, Trakia University, Stara, Bulgaria
}

\begin{abstract}
In the modern economy business failures are a matter of great concern to entrepreneurs. The purpose of this article is to predict the possibility of a deterioration in the financial situation and bankruptcy of companies.

Bankruptcy models are a common tool for financial analysis and the ability to predict the risk of corporate insolvency and bankruptcy.

The four-factor Taffler model is one of the applied risk assessment models for bankruptcy, also known as "Z-score analysis". The study presents the main points of the development of the model, examining the advantages, disadvantages and problems that arise from its implementation.

The subject of the study are companies from the food industry in the Stara Zagora Region with main production and processing of meat and meat products and manufacture of vegetable and animal oils and fats for the period 2013-2017.
\end{abstract}

Key words: Taffler "Z-score model", financial analysis, instability and risk of bankruptcy, food industry.

\section{INTRODUCTION}

Process industry is the most important sector of the industry in Bulgaria and plays a significant role in the gross domestic product (GDP).

The food industry, through the production and processing of food products, beverages and non-durable consumer goods, is part of the manufacturing industry and performs relatively better than other industries in the survey period. The reason is that capital goods and intermediate goods are more susceptible to business cycle fluctuations from industries producing essential goods and non-durable consumer goods whose demand is less sensitive to change - these are goods with less chance of replacement.

In the specialized literature it is recommended to use formal and informal criteria for analysis and assessment of the violations in the financial sustainability and to predict the

\footnotetext{
*Correspondence to: Oleg Milev PhD, Trakia University of Stara Zagora, Faculty of Economics, Department "Economics”, Bulgaria, Stara Zagora, Student campus, +35942699 431, E-mail: milev@uni-sz.bg
}

insolvency of the companies. The distortion of financial sustainability in companies leads to a crisis which ends up as bankruptcy.

Formal criteria are financial ratios, combined in models, levels and dynamics, which can justify conclusions about the likelihood of insolvency, and eventually- of crisis and bankruptcy. The earliest models for predicting the risk of business insolvency were onedimensional. Subsequently, they have got more complicated involving a larger number of indicators. (1)

Informal criteria are characteristics of a worsening financial condition, which in most cases are not quantified. The most popular in this area is the financial risk forecasting and bankruptcy risk model developed by John Argenti 40 and known as the A- model (Argenti failure model, 1976). The model encompasses distinct features inherent in the business, moving along the line "Insolvency Crisis - Bankruptcy". Their subjective ballistic evaluation calculates a total ball, from which one can judge the existence of tendencies in the companies leading to bankruptcy. (2) 
Companies' insolvency research dates back to the late 1930s in the United States. At the beginning of the twentieth century a number of researchers were dealing with bankruptcy problems. For example, analyzing 183 companies experiencing financial difficulties between 1921 and 1930, R.F. Smith and A.H. Winakor suggested that the most reliable indicator of forthcoming bankruptcy is to reduce the ratio between net turnover working capital and total assets. (3)

The first attempt to develop a model using financial ratios to predict insolvency was developed by Beaver (1966). Afterwards, a series of models for solving the problem started by analyzing a group of companies surveyed on pre-selected qualitative characteristics (financial ratios). Most of the successful research in this area is brought to life through the use of discriminatory multifactor models developed by multidimensional discriminant analysis. (4)

A significant group of models for prediction the probability of bankruptcy are the Z-models developed by Edward Altman, who is often

$$
\begin{aligned}
& Z=0,53 x_{1}+0,13 x_{2}+0,18 x_{3}+0,16 x_{4} \\
& x_{1}=\frac{\text { Profit before tax }}{\text { Current liabilities }} \text {, where: } \\
& x_{2}=\frac{\text { Current assets }}{\text { Total liabilitiesви }} \\
& x_{3}=\frac{\text { Total assets }}{\text { To............. }} \\
& x_{4}=\frac{\text { Sales }}{\text { Total assets }}
\end{aligned}
$$

Interpretation of results is related to the following dependencies:

$\mathrm{Z}>0,3$ - low likelihood of bankruptcy$$
Z=0,2-0,3-\text {, grey zone" (undefined) }
$$$$
\mathrm{Z}<0,2 \text { - almost a bankrupt. }
$$

\section{ANALYSIS AND EVALUATION OF BANKRUPTCY RISK ACCORDING TO THE TAFFLER MODEL}

Analysis is held onto two of the sub-branches of the food industry. Three of the companies surveyed are from the "Processing and preserving of meat and production of meat products" sub-sector and two from the subsector "Manufacture of vegetable and animal oils and fats". The observation period is 5 years (2013-2017).

There are many other companies from the food industry in the region that are not included in called the "father" of modern theory of bankruptcy prediction. This includes the twofactor, 5-factor, and 7-factor $\mathrm{Z}$ models. (5)

Z-score models are a set of suitably selected weighted odds. If the estimate is above the threshold, then the company is classified as financially healthy and below this threshold is considered as a risk.

Taffler's model was proposed in 1977 and is a four-factor predictive model. It is recommended for taking into account the current trends in business and the impact of prospective technologies on the structure of financial indicators.

Taffler's model is composed of a combination of the best set of ratios, which together with an appropriate added force produce the necessary result. Through these ratios, the four key dimensions of the company's financial profile, such as $\mathrm{x}_{-} 1$ - measures Profitability with 53\% weight, x_2 - Working capital position - 13\%, x_3 - Financial risk - 18\% and x_4 - Liquidity - $16 \%$. The Taffler model can also be displayed as a linear equation. (6)

this study due to their low market share (less than $1 \%$ ).

The Taffler model is not the best one that can be used but is best suited to the current industry-specific design, and the data we have available is best applied. With the four factors used, it covers the accuracy of the prediction.

Table 1 summarizes the main economic indicators, with information for the companies in the subsector "Production and processing of meat and meat products" marked with "A" and the companies from the sub-sector "Production of vegetable and animal oils and fats" with "B". 
From the outputs of the four factors included in the Taffler model shown in the table it can be summarized that during the period 2013-2017 there is no risk of bankruptcy of the companies involved in these subsectors, since throughout all years the value of $Z$ ranges from 0,2501 to 1,4484 , which is greater than 0.2 , which is out of the risk area for bankruptcy.
The lowest values in the so-called "gray zone" of 0.2 to 0.3 as shown in Table $\mathbf{1}$ are in the first company of the sub-sector "Production and processing of meat and meat products" marked with A1 at the beginning of the period. In the coming years, the company has increased the $\mathrm{Z}$ indicator and thus exit the risk zone, reaching 0.3835 at the end of the period.

Table 1. Outputs of financial indicators in the food industry sub-sectors $A$ and $B$ in the period 20132017

\begin{tabular}{|c|c|c|c|c|c|c|}
\hline \multirow{2}{*}{ Financial indicators } & \multirow{2}{*}{ Years } & \multicolumn{5}{|c|}{ Companies } \\
\hline & & A1 & A2 & A3 & B1 & B2 \\
\hline \multirow{5}{*}{$x_{1}=\frac{\text { Profit before tax }}{\text { Current liabilities }}$} & 2013 & 0,0000 & 0,3914 & 0,1989 & 0,8280 & 0,0172 \\
\hline & 2014 & 0,0000 & 0,0900 & 0,2546 & 0,4760 & 0,0224 \\
\hline & 2015 & 0,0000 & 1,2092 & 0,2961 & 0,4114 & 0,0213 \\
\hline & 2016 & 0,0000 & 1,8067 & 0,3201 & 0,0149 & 0,0383 \\
\hline & 2017 & 0,0813 & 1,3070 & 0,3048 & 0,4886 & 0,0255 \\
\hline \multirow{5}{*}{$x_{2}=\frac{\text { Current assets }}{\text { Total liabilities }}$} & 2013 & 0,3004 & 0,3702 & 0,4784 & 0,7101 & 0,8424 \\
\hline & 2014 & 0,2865 & 0,4361 & 0,4606 & 0,7948 & 0,8299 \\
\hline & 2015 & 0,3016 & 0,3221 & 0,4747 & 0,8516 & 0,8379 \\
\hline & 2016 & 0,3307 & 0,3848 & 0,4387 & 0,8565 & 0,8401 \\
\hline & 2017 & 0,3676 & 0,3502 & 0,2613 & 0,7826 & 0,8594 \\
\hline \multirow{5}{*}{$x_{3}=\frac{\text { Current liabilities }}{\text { Total assets }}$} & 2013 & 0,2084 & 0,2230 & 0,4586 & 0,0646 & 0,7414 \\
\hline & 2014 & 0,1513 & 1,7558 & 0,4923 & 0,1410 & 0,7097 \\
\hline & 2015 & 0,2452 & 0,2054 & 0,4924 & 0,2516 & 0,7291 \\
\hline & 2016 & 0,3009 & 0,1919 & 0,4829 & 0,2541 & 0,7348 \\
\hline & 2017 & 0,3035 & 0,2350 & 0,1594 & 0,0490 & 0,7795 \\
\hline \multirow{5}{*}{$x_{4}=\frac{\text { Sales }}{\text { Total assets }}$} & 2013 & 1,0845 & 2,2903 & 0,8324 & 1,5218 & 1,1223 \\
\hline & 2014 & 1,4144 & 2,2660 & 0,7055 & 1,0087 & 0,9534 \\
\hline & 2015 & 1,5430 & 2,9239 & 0,8230 & 0,8903 & 1,2083 \\
\hline & 2016 & 1,5156 & 2,5394 & 0,7592 & 0,7852 & 1,4791 \\
\hline & 2017 & 1,4868 & 2,9318 & 0,4924 & 0,8824 & 1,1391 \\
\hline \multirow{5}{*}{$\begin{array}{c}Z=0,53 \cdot x_{1}+0,13 \cdot x_{2}+0,18 \cdot x_{3} \\
+0,16 \cdot x_{4}\end{array}$} & 2013 & 0,2501 & 0,6622 & $\mathbf{0 , 3 8 3 4}$ & $\mathbf{0 , 7 8 6 3}$ & $\mathbf{0 , 4 3 1 7}$ \\
\hline & 2014 & 0,2908 & $\mathbf{0 , 7 8 3 0}$ & 0,3963 & 0,5424 & 0,4001 \\
\hline & 2015 & $\mathbf{0 , 3 3 0 2}$ & 1,1875 & $\mathbf{0 , 4 3 8 9}$ & 0,5165 & 0,4448 \\
\hline & 2016 & $\mathbf{0 , 3 3 9 6}$ & 1,4484 & 0,4351 & 0,2906 & $\mathbf{0 , 4 9 8 4}$ \\
\hline & 2017 & $\mathbf{0 , 3 8 3 5}$ & 1,2497 & $\mathbf{0 , 3 0 3 0}$ & $\mathbf{0 , 5 1 0 7}$ & 0,4478 \\
\hline
\end{tabular}

In the other two companies in the same subsector marked as A2 and A3 the indicators are marked very good, there is no risk of insolvency and bankruptcy. The tendency is increase in those indicators, which from 2015 exceed 1 and reach their highest values in 2016, respectively, 1,4484 .

The third company (A3) has relatively constant indicators, with the best results of this company being observed in the middle of the survey period (2015-2016).

In the second group of companies in the subsector "Production of vegetable and animal oils and fats" named with (B) the data shows that they are out of the risk limit and accordingly there is no risk of adverse financial consequences and bankruptcy. Although the $\mathrm{Z}$ indicator is not the highest compared to the previous companies, there is a tendency towards the continuity and security of financial discipline (0.4001-0.4984).

For greater credibility and visibility, the data in Table $\mathbf{1}$ is illustrated graphically in Figure 1, with the companies horizontally mapping over the period under review, and the corresponding $\mathrm{Z}$-score analyzer scores vertically. 


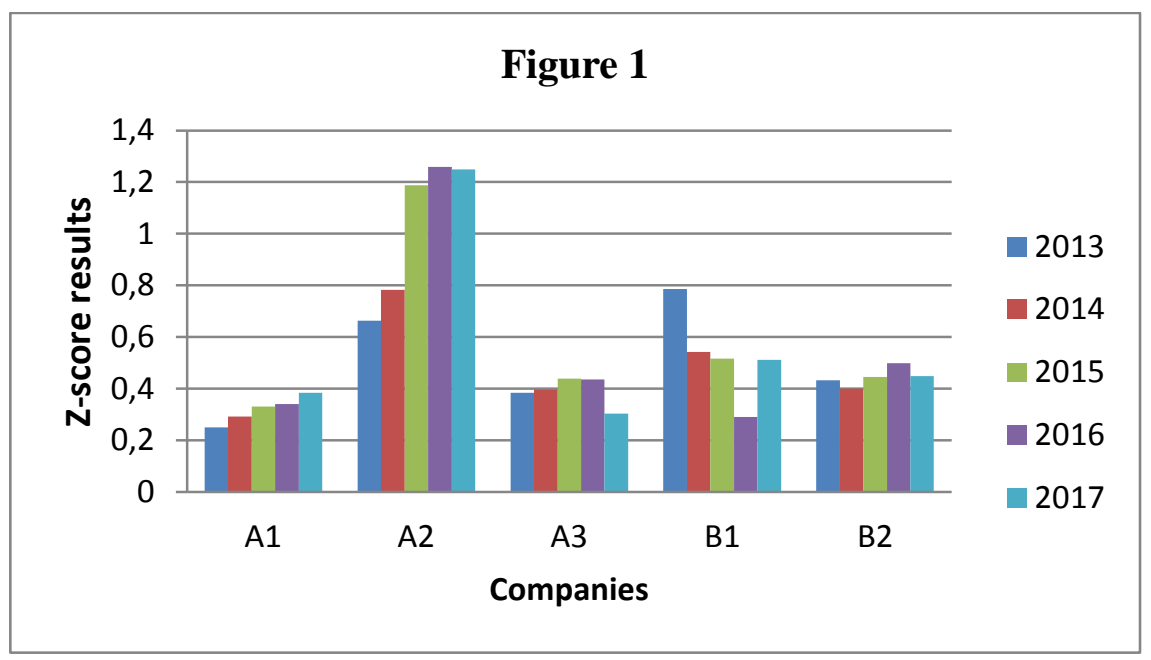

Figure 1. Results of the food industry companies in 2013-2017

As a whole, the graphical expression shows the relative stability of the financial indicators of the different companies in the two sub-sectors ranging from approximately 0.3 to 0.5 , with the exception of the company A2, which at the end of the period 2015-2016 sharply increased its results reaching and surpassing coefficient 1.

In general, the studied food sector subsectors with few exceptions show good results in the Taffler model analysis. There are well regulated economic indicators and a stable level of the financial condition of the companies, which is a prerequisite for the lack of indications of bankruptcy. It is also indicative that the values of the coefficient $\mathrm{Z}$ of the four-factor model are higher than the riskdetermined in the model used.

\section{CONCLUSION}

The analytical information presented in the application of the four-factor Taffler model allows us to make the following conclusions about the state of the food industry:

Despite the slight fluctuations at the beginning of the period, the results of the analysis show a relatively stable financial situation and a lack of bankruptcy of the surveyed companies.

The modeling methodology does not take account of sectoral differences, which adversely affects their flexibility and adaptability, and this may lead to unnecessary optimism or excessive pessimism in individual cases.

- The effectiveness of the survey will increase significantly if it is complemented by models and indicators specific to the financial analytical model. Thus, financial sustainability will be measurable on the one hand, from balance and profit positions, on the other hand, from capital market positions, investment risk and shareholder value.

\section{REFERENCES}

1. Kasarova, V., Models and indicators of analysis on the company`s financial stability, Scientific electronic archive of NBU.

http://eprints.nbu.bg/637/1/FU_1_FINAL.p df $\} \mathrm{kr}$.

2. Argenti J. Corporate Collapse. The Causes and Symptoms, 1976 Publisher: London; New York: McGraw-Hill; An electronic document:

http://www.accaglobal.com/pubs/students/p ublications/student_accountant/archive/sa_j j08_mpogue.pdf.

3. Smith, R. F., \& Winakor, A. H. (1935). Changes in the Financial Structure of Unsuccessful Industrial Corporations. Bureau of Business Research Bulletins, 51, $1-44$.

4. Beaver, W. H. (1968). Alternative Accounting Measures as Predictors of Failure. The Accounting Review, 43(1), 113-122.

5. Altman, E.I., Haldeman, R., Narayanan, P., 1977. Zeta analysis: A new model to identify bankruptcy risk of corporations. Journal of Banking and Finance 29-54.

6. Taffler, R.J. (1977), "Finding those companies in danger using discriminant analysis and financial ratio data: a comparative based study city business school", City University Business School, London, Working Paper No. 3 